\title{
Light-emitting Diodes versus Compact Fluorescent Tubes for Phototherapy in Neonatal Jaundice: A randomised control trial
}

\author{
Reddy TR ${ }^{1}$, Prasad PK ${ }^{2}$, Parakh $\mathbf{H}^{3}$, Nagar $\mathrm{P}^{4}$ \\ ${ }^{1}$ Dr T Raghunath Reddy, Cosultant Pediatrics, ${ }^{2}$ Dr P Krishna Prasad, Cosultant Pediatrics, ${ }^{3}$ Dr Hemant parakh, Consultant \\ Peditrics, ${ }^{4}$ Dr Pritesh nagar, Consultant Pediatric Intensivist, Aditya Hospital Hyderabad, Telangana, India
}

Address for correspondence: Dr Pritesh Nagar, Email: priteshnagar@gmail.com

\begin{abstract}
Introduction: Newer light emitting diodes (LED) phototherapy units have become indigenous part in the management of neonatal hyperbilirubinemia almost replacing the conventional compact fluorescent light (CFL) units. Only few studies from India available compare the efficacies of two, so a randomised control study was undertaken. Methods: 60 healthy neonates $\geq 35$ weeks gestational age were randomised into CFL and LED groups using computerised random number sequence. The rate of fall of bilirubin levels at 6 hours and at completion along with total duration of phototherapy in both groups was measured. Results analysed by standard statistical methods. Results: LED phototherapy units showed higher rate of fall bilirubin at $6 \mathrm{hrs}$ (LED $0.41 \pm 0.10 \mathrm{mg} / \mathrm{dl} / \mathrm{hr}$ VS CFL $0.23 \pm 0.17 \mathrm{mg} / \mathrm{dl} / \mathrm{hr}$, C.I $=95 \%, \mathrm{p}<0.05$ ) and after completion of therapy (LED $0.29 \pm 0.08 \mathrm{mg} / \mathrm{dl} / \mathrm{hr}$ VS CFL $0.19 \pm 0.06 \mathrm{mg} / \mathrm{dl} / \mathrm{hr}$ with $\mathrm{p}<0.05$ C.I $95 \%$ ) compared to CFL group. There was no statistically significant difference in total duration of therapy in both the groups (LED 18.8 $\pm 8 \mathrm{hrs}$ VS CFL $20 \pm 6 \mathrm{hrs}$ C.I $=95 \%$ $\mathrm{p}=0.56$ ). 2 among CFL group had failure of phototherapy whereas 1 was lost to follow up in LED group. Both groups didn't show any side effects. Conclusion: The LED phototherapy units are more efficacious in terms of higher rate of fall of bilirubin levels in similar time duration compared to CFL units. But the total duration of phototherapy was equal; it can be because there was significant difference between both the groups in terms of bilirubin levels at start and at end of therapy which couldn't be prevented even after effective randomisation.
\end{abstract}

Key words: Phototherapy, Neonatal jaundice, Neonatal hyyperbilirubinemia

\section{Introduction}

Neonatal hyperbilirubinemia is one of the common conditions encountered in day to day practice. Approximately $60 \%$ of term and $80 \%$ of preterm babies develop jaundice in the first week of life, and about $10 \%$ of breast fed babies are still jaundiced at 1month of age. Jaundice occurs in new born physiologically and becomes visible on the $2 \mathrm{nd}$ or $3 \mathrm{rd}$ day, usually peaking between the $2 \mathrm{nd}$ and 4 th days at 5-6 mg/dL and decreasing to $<2 \mathrm{mg} / \mathrm{dL}$ between the 5 th and 7 th days of life. This physiological jaundice is due to shorter life span of circulating RBCs resulting in increased destruction along with transient impairment of the neonatal liver for conjugation of the bilirubin. It was found that overall $6-7 \%$ of full-term infants have indirect bilirubin levels $>13 \mathrm{mg} / \mathrm{dL}$ and less than $3 \%$ have levels $>15 \mathrm{mg} / \mathrm{dL}[1]$.

Jaundice is considered pathological if it appears in the first 24-36 hours of life, serum bilirubin rising at a rate faster than $5 \mathrm{mg} / \mathrm{dL} / 24 \mathrm{hr}$, jaundice persists after 10-14 days of life, direct bilirubin fraction is $>2 \mathrm{mg} / \mathrm{dL}$ at any Manuscript received: $11^{\text {th }}$ Jan 2015

Reviewed: $16^{\text {th }}$ Jan 2015

Author Corrected: $29^{\text {th }}$ Jan 2015

Accepted for Publication: $11^{\text {th }}$ Feb 2015

Pediatric Review: International Journal of Pediatric Research time. Other factors suggesting a non-physiologic cause of jaundice are family history of haemolytic disease, pallor, hepatomegaly, splenomegaly, failure of phototherapy to lower the bilirubin level, vomiting, lethargy, poor feeding, excessive weight loss, bradycardia, abnormal vital signs (including hypothermia), light coloured stools, dark urine positive for bilirubin, and signs of kernicterus [1][3][5].

The most dreaded complication of neonatal jaundice is kernicterus which is due to deposition of bilirubin in the brain causing yellowish discoloration of the brain, leading to bilirubin encephalopathy[2][3]. The exact level of bilirubin that is likely to cause neurotoxicity in any baby varies, and depends on the interplay of the multiple factors which includes acidosis, gestational and postnatal age, and rate of rise of serum bilirubin, serum albumin concentration, and concurrent illness. Asian babies being are at higher risk due to breast-feeding, variant-glucuronosyl transferase activity (1A1), and alterations of the organic anion transporter 2 gene[1] Bilirubin which is produced by the catabolism of haemoglobin is conjugated in liver and further excreted into the intestines. Immaturity of the hepatic glucuronosyltransferase and inadequate milk intake causes delayed clearance of bilirubin. Within the Available online at: www.pediatricreview.in 72 | P a g e 
Research Article

reticuloendothelial system, heme is broken down into biliverdin and carbon monoxide. Biliverdin is reduced to bilirubin by biliverdin reductase. Unconjugated bilirubin binds to albumin and transported to liver where it is conjugated by glucuronosyltransferase to bilirubin diglucuronide, which is water soluble and easily excreted by the liver and biliary tract. In the intestine, some bilirubin may be converted back to its unconjugated form by a glucuronidase and reabsorbed by the intestine. Increased levels of unconjugated bilirubin levels can cross blood brain barrier and can cause kernicterus. It is vital to treat hyperbilirubinemia at lower levels to prevent developing of kernicterus.

There are many modalities available in the treatment of neonatal jaundice. Among them the time tested ones are exchange transfusion and phototherapy. Exchange transfusion is done since late 1930s and is one of the most practiced methods in bringing down the bilirubin levels. The main advantage of exchange transfusion is that it can rapidly decrease the bilirubin levels to safe levels. Potential complications from exchange transfusion include metabolic acidosis, electrolyte abnormalities, hypoglycemia, hypocalcemia, volume overload, graft versus host disease etc[3][4].

Phototherapy being non-invasive, cheap, safe and with fewer side effects have become the treatment of choice for the management of neonatal jaundice worldwide[5][6][7]. Phototherapy causes conversion of bilirubin levels into water soluble isomers which are excreted in urine through photooxidation, configurational isomerisation and structural isomerisation. Phototherapy uses light in range of blue-green spectrum $(400-520 \mathrm{~nm})$ [8][9][10][11] since the beginning of the phototherapy as the treatment of neonatal jaundice many novel light sources were developed and used. Among them the most popularly used ones are halogen spot light, fluorescent lamp devices, fiberoptic pads, compact fluorescent tubes and the latest ones light emitting diodes. The problems with the initial light sources were they were large, produced excessive heat and with poorer irradiance levels and requirement of frequent replacement of the tubes or bulbs [12][13].

Among the light sources mentioned above the most commonly sources used worldwide now days are conventional compact fluorescent light units followed by which newly developed light emitting diode phototherapy units. Compact fluorescent light units are less space occupying had higher irradiances and have lower power consumption compared to older units. The problems of significant heat production was still pertaining along with emission of unstable broad wavelength, requirement of frequent assessment of irradiance and timely change of the light units[14][15][16][17][18].

LED phototherapy units which were developed in late 90's by incorporating gallium nitrite light emitting diodes proved to be giving higher irradiance with cheaper cost, less heat production, extended life span, narrow spectrum wavelength, duration of change of bulbs nearly 20,000 hours compared to 2000 hours of conventional fluorescent lights. In theory these lights are far superior to conventional phototherapy units[19][20]. Since the incorporation of LED phototherapy units in the management of neonatal jaundice large number of studies have been done worldwide comparing the efficacies with different light sources. But only few published studies are available from India comparing compact fluorescent light units with LEDs[21]. Theoretically speaking LED phototherapy units are better and more efficacious in treatment of neonatal jaundice. Hence, we conducted this study to answer the question "whether LED phototherapy is as efficacious as the standard compact fluorescent light (CFL) phototherapy in management of healthy term and late preterm neonates with non-haemolytic jaundice".

\section{Method}

This was a single centre randomized controlled trial conducted in neonatal intensive care unit of Aditya hospital Hyderabad from January 2013 to May 2014. The study protocol was approved by institutional ethics committee of Aditya hospitals. A written informed consent was obtained from one of the parents after explaining about the present study through the subject information sheet.

\section{Subjects}

Newborn infants born at 35 or more completed weeks of gestation were eligible for enrolment, if they developed hyperbilirubinemia needing phototherapy within first 7 days of life. The decision to start phototherapy was made by bedside physicians on the basis of institutional protocol devised from American Academy of Paediatrics guidelines[23], National Neonatology forum guidelines[25] and Bhutani et al normograms[22] [24]. Phototherapy was stopped when serum total bilirubin levels were measured less than $12 \mathrm{mg} / \mathrm{dl}$ (as per American academy of paediatrics guidelines [23] and by the institutional protocol).

\section{Exclusion Criteria}

Infants with perinatal asphyxia (Apgar score $<4$ at 1 minute or $<7$ at 5 minute), onset of jaundice within $24 \mathrm{~h}$ of age, evidence of haemolysis (positive direct Coombs test), rhesus haemolytic disease, culture-positive or 
clinical sepsis, need for exchange transfusion at the time of enrolment, and major congenital malformations, already received phototherapy, high direct hyperbilirubinemia, age $<1 \mathrm{~d}$ or $>7$ days, gestational age $<35$ weeks, infants of diabetic mother, neonates with hypothyroidism and those who refused to give consent were excluded from the study.

\section{Intervention}

Enrolled infants were randomized to receive single surface LED or CFL phototherapy. Allocation of infants into 2 groups was done by using a web-based random number generator. A written informed consent was obtained from parents before enrolment. The LED phototherapy units (LED PT 100, Phoenix India Pvt Ltd) had 6 LED bulbs arranged in an area of about $68 \times 90 \mathrm{~cm}$. The unit was having emission spectral wavelength between $450-460 \mathrm{~nm}$.

Commercially available CFL units consisting of 6 special blue compact fluorescent bulbs were used for the study. Two phototherapy units of CFL type and one LED were designated as 'study machines' for the study cohort. New lamps were installed in all the units at the start of the study. Irradiance was measured at the start of study and there after every 6 months till the completion of study. Irradiance was measured with Ohmeda's Biliblanket Meter II. In both the groups, each enrolled neonate received phototherapy using a single overhead phototherapy unit. A distance of $35 \mathrm{~cm}$ was maintained between the baby and the lamp surface for both types of units.

\section{Outcome variables}

The rate of fall of bilirubin and the duration of phototherapy were the primary outcomes. Rate of fall of bilirubin was calculated at 6 hours and after completion of total duration of intervention. The total duration of phototherapy was calculated by subtracting age at start of phototherapy from age at end of phototherapy in hours. There were brief periods of discontinuation of phototherapy for the purpose of feeding or changing nappy and were not excluded while calculating total duration. The secondary outcomes analysed were failure of phototherapy, occurrence of hypothermia or hyperthermia and rashes. 'Failure of phototherapy' was defined as serum total bilirubin levels rising bilirubin level above the bilirubin at beginning after 6 hours of phototherapy or bilirubin levels reaching exchange transfusion.

\section{Data collection and monitoring}

Clinical monitoring was done for side effects of phototherapy like dehydration and skin rash; and a periodic axillary temperature measurement was done to detect episodes of hypothermia or hyperthermia. Serum total bilirubin was initially measured at 6 hours later it was measured every 12 th hourly till intervention was completed, using samples collected by prick method and sent for biochemical analysis. Bilirubin levels were analysed by Konelab 20 analyser using photometric test using 2-4dichloroaniline method.

\section{Sample size}

There is limited data from Indian studies regarding the comparison of compact fluorescent light and LED light units for hyperbilirubinemia in neonates. Hence a proper sample size could not be generated by standard statistical methods. Instead we included 30 subjects in each group; where sample size 30 is large number as far as statistical theory (central limit theorem, probability theory) is concerned[26]. Total sample size of 60 neonates was taken.

\section{Statistical analysis}

Data entry and analysis were done using Windostat Version 9.2 software. Continuous data with normal distribution was analysed by student t-test and nonnormally distributed data by Mann Whitney U test. Categorical data was analysed by chi-square or Fisher exact test. A P value of $<0.05$ was taken as significant. The study was conducted as per protocol.

\section{Results}

The study enrollment is depicted in Table 1.

During the study there were 2 subjects in CFL group who had failure of phototherapy and one neonate was lost to follow up in LED group. As the study was conducted as per protocol, the results of the above 3 neonates was not included in the final analysis. The two groups were comparable with each other in terms of birth weight, gestational age, sex, age at the start of phototherapy, weight at the start of phototherapy (Table 2).

There was significant difference in the bilirubin levels at the beginning of phototherapy in both groups. the bilirubin levels were higher in LED group (16.2 $\pm 1.8 \mathrm{mg} / \mathrm{dl})$ compared to CFL group $(15 \pm 1.4 \mathrm{mg} / \mathrm{dl})$. The bilirubin levels at the end of phototherapy were significantly lower in LED group $(10.8 \pm 0.74 \mathrm{mg} / \mathrm{dl})$ compared to CFL group $(11.25 \pm 0.57 \mathrm{mg} / \mathrm{dl})$.

There was higher rate of fall of bilirubin levels after 6 hours of continuous phototherapy. (Table 3) The mean was LED $(0.41 \pm 0.10 \mathrm{mg} / \mathrm{dl} / \mathrm{hr})$ VS CFL $(0.23 \pm 0.18$
Available online at: $\underline{w w w}$.pediatricreview.in
74 | P a g e 
$\mathrm{mg} / \mathrm{dl} / \mathrm{hr}) \mathrm{p}<0.05$ C.I $95 \%$. Similarly there was higher rate of fall of bilirubin levels for entire duration of phototherapy. The mean was LED $(0.29 \pm 0.08 \mathrm{mg} / \mathrm{dl} / \mathrm{hr})$ VS CFL $(0.20 \pm 0.06 \mathrm{mg} / \mathrm{dl} / \mathrm{hr}) \quad \mathrm{p}<0.05$ C.I $95 \%$. Total duration of phototherapy for both the groups didn't show statistically significant difference. The mean was LED (18.8 \pm 8$)$ VS CFL $(20 \pm 6) \mathrm{p}=0.56$ C.I $95 \%$. There were no side effects noted in any of the neonate enrolled in the study.

\section{Chart 1: Patient selection process}

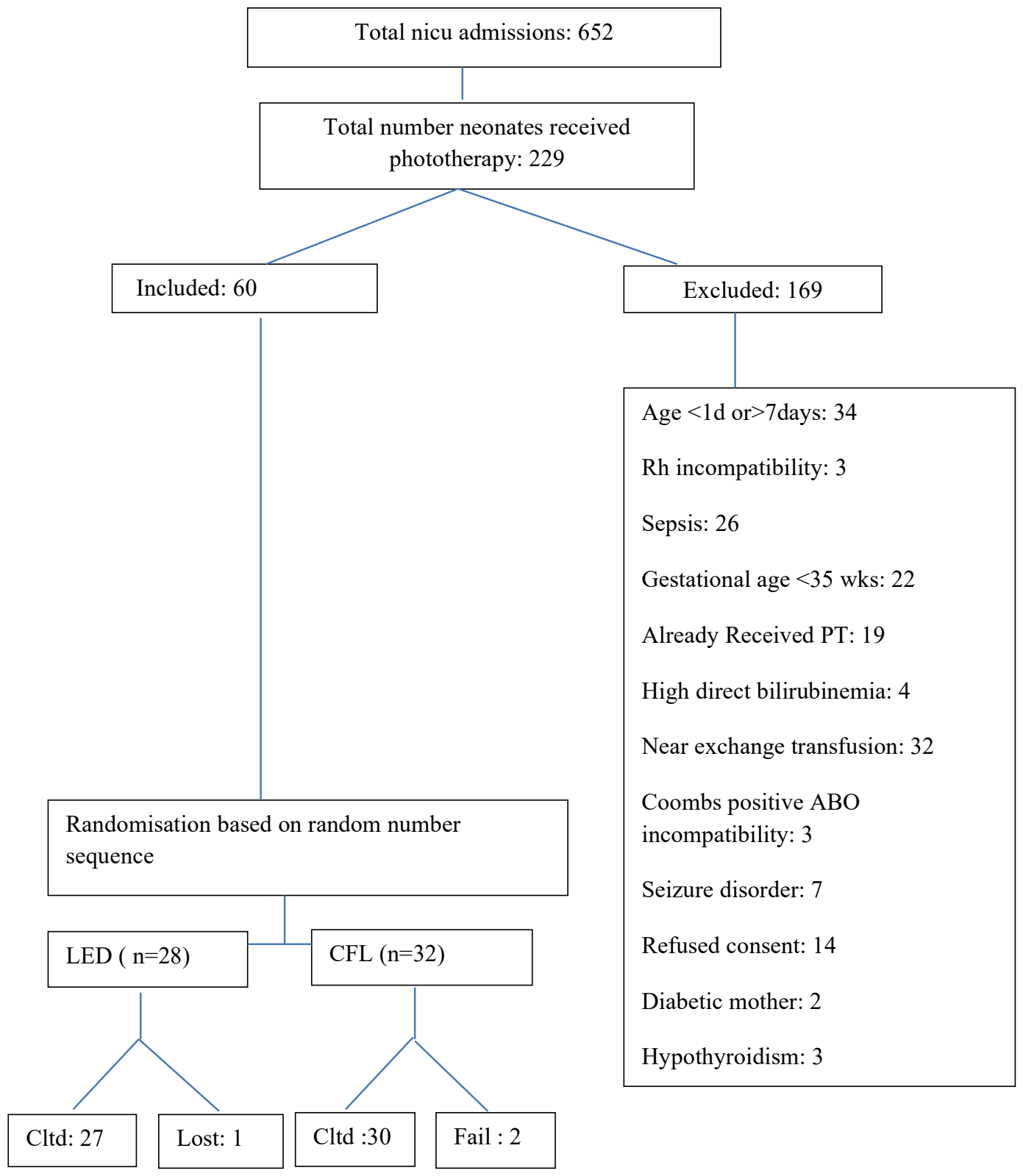


Table 2: Comparision of baseline characterstics in both groups

\begin{tabular}{|l|l|l|l|}
\hline & Led $(\mathbf{n}=\mathbf{2 8})$ & Cfl $(\mathbf{n}=\mathbf{3 2})$ & P \\
\hline Birth weight $(\mathrm{kg})$ & $2.93 \pm 0.37$ & $2.81 \pm 0.35$ & 0.23 \\
\hline Male/female & $13 / 15$ & $12 / 20$ & \\
\hline Gestational age $(\mathrm{wks})$ & 38 & 37 & 0.22 \\
\hline Age at start $($ days $)$ & 4.62 & 4.64 & 0.95 \\
\hline Weight at start $(\mathrm{kg})$ & $2.69 \pm 0.38$ & $2.64 \pm 0.38$ & 0.61 \\
\hline Weight at end $(\mathrm{kg})$ & $2.69 \pm 0.38$ & $2.66 \pm 0.35$ & 0.72 \\
\hline Bilirubin at start(mg/dl) & $16.2 \pm 1.8$ & $15.0 \pm 1.4$ & $\mathbf{0 . 0 0 6}$ \\
\hline Bilirubin at end $(\mathrm{mg} / \mathrm{dl})$ & $10.8( \pm 0.74)$ & $11.25 \pm 0.57$ & $\mathbf{0 . 0 3}$ \\
\hline Pcv at beginning & 49.8 & 53.7 & \\
\hline Pcv at end & 48.4 & 52.4 & \\
\hline Irradiance $\left(\mu \mathrm{W} / \mathrm{cm}^{2} / \mathrm{nm}\right)$ & & & \\
At beginning & 65 & 25 & \\
\hline At the end & & & \\
\hline
\end{tabular}

Table 3: Comparision of final results and analysis

\begin{tabular}{|l|l|l|l|}
\hline & Led $(\mathbf{n}=\mathbf{2 8})$ & Cfl (n=32) & P \\
\hline Rate of fall of billirubin after 6hours & $0.41( \pm 0.10)$ & $0.23( \pm 0.18)$ & 0.00002 \\
\hline Rate of fall of bilirubin during total & $0.29( \pm 0.08)$ & $0.20( \pm 0.06)$ & 0.00001 \\
\hline Total duration (hrs) & $18.8( \pm 8)$ & $20 \pm 6$ & 0.56 \\
\hline Failure of phototherapy & 0 & 2 & \\
\hline
\end{tabular}

\section{Discussion}

The management of neonatal jaundice which is potentially a benign condition have been changing over years. Higher blirubin levels if allowed to circulate in the blood for longer duration can cause irreversible damage to brain especially in preterm babies due to immaturity of blood brain barrier to prevent seepage of unconjugated bilirubin entering in to the brain. Thus it is essential for the rapid assessment and prevention of unconjugated bilirubin levels reaching levels which can cause brain damage. Exchange transfusion brings down bilirubin levels effectively but it had its own potential complications and side effects. Phototherapy being non invasive and safe method has been used since decades in decreasing neonatal hyperbilirubinemia. There is gradual evolution and improvement in the types of light sources, gradually decreasing the drawbacks like poor irradiance, excessive heat production, poor durability etc since advent of phototherapy[2][4][12][22].

Among phototherapy devices being used worldwide, the newer devices i.e; compact fluorescent lights and light emitting diode phototherapy units have almost replaced most of the older devices. Their compactness, decreased heat production and ability to deliver irradiance at constant levels made them suitable to be used even in preterm babies who are most vulnerable for temperature and humidity changes. Their efficacy in bringing down bilirubin levels which have been assessed in multiple studies done worldwide have helped in decreasing the need for exchange transfusions and its potential complications. Among the compact fluorescent light units and light emitting diode units, LED units are better in terms of higher irradiance, at cheaper cost, less heat production, extended life span, narrow spectrum wavelength, compared to conventional fluorescent lights. In theory so far these lights are far superior to conventional phototherapy units [12][13].

The present study compared compact fluorescent lights (CFL) and high intensity Light emitting diode (LED) lights used for phototherapy. In the present study conducted on 60 babies, high intensity LED phototherapy was found to be more effective than conventional fluorescent phototherapy with respect to bilirubin photo degradation. During the study it was found that there was higher rate of fall of bilirubin levels after 6 hours of continuous phototherapy. Similarly there was higher rate of fall of bilirubin levels for entire duration of phototherapy. Total duration of phototherapy for both the groups didn't show statistically significant difference. This is explained by the observation that the mean

Available online at: www.pediatricreview.in 76 | P a g e 
Research Article

bilirubin levels at start of therapy were significantly higher in the LED group compared to CFL group. Also, the bilirubin level at the end of therapy was significantly lower in LED group compared to CFL group. This bias couldn't be eliminated even after effective randomisation. LED group showed higher efficacy than CFL group. The study was conducted as per protocol so the subjects who had failure of phototherapy and those lost to follow up were not included in final analysis.

There was no significant change in the haematocrit of neonates in both the groups during the study. There were no rashes observed in any of subject during study, no incidence of hypothermia, hyperthermia during the period of study.

In comparison to previous studies one done by Kumar et al[27][28] a multicentre trial for comparison LED and CFL showed that the two groups were equally efficacious in terms of rate of fall of bilirubin and total duration of phototherapy. The median duration of phototherapy (IQR) in the two groups was comparable $(26(22-36) \mathrm{h}$ vs. $25(22-36) \mathrm{h} ; P=0.44)$. The rate of fall of serum total bilirubin (STB) during phototherapy and the incidence of 'failure of phototherapy' were also not different. Similar proportion of neonates had a rebound increase in serum total bilirubin needing restarting of phototherapy. Martin s et al [29] adjusted the devices to obtain a similar exposed surface area and found that higher irradiance in the LED group resulted in a better efficacy. In Belma Saygýlý Karagöl et al [30] study on CFL and LED phototherapy units and observed that there were significant differences in the absolute change in serum bilirubin level per hour (CFL $0.13 \pm 0.1 \mathrm{mg} / \mathrm{dl} / \mathrm{hr}$ VS LED $0.30 \pm 0.2 \mathrm{mg} / \mathrm{dl} / \mathrm{hr}$ $\mathrm{p}=0.003$ ) and relative change in serum bilirubin level at 24 hour between CFL and LED $(p<0.05)$. Duration of phototherapy was shorter in the LED phototherapy group but this was not statistically significant. As per Cochrane review [29] LED and CFL light sources were comparable in pooled estimates of duration of phototherapy ( 0.29 hours, $95 \% \mathrm{CI}-1.31$ to 1.8 ) as well as the rate of decline of serum total bilirubin $(0.01 \mathrm{mg} / \mathrm{dL} / \mathrm{hour}, 95 \%$ CI -0.03 to 0.04 ) concluding the two units equally efficacious. Study done by J.Viau Colindres et al [31] LED phototherapy using low-cost set of LED lights found that these lights were as effective as conventional phototherapy in the treatment of neonatal hyperbilirubinemia.

Although phototherapy has been used for the treatment of neonatal hyperbilirubinemia for more than 40 years, a method with least side effects and maximum efficacy is yet to be developed. There is a need to conduct costbenefit analysis of different phototherapy devices. There is also a need for studies to compare different types of LED devices. The present study has demonstrated that LED units can cause a greater fall of bilirubin levels in a unit time compared to CFL units. So we propose that LED units can be used with better efficacy when bilirubin levels nearing exchange transfusion or in preterms but further studies are required to confirm the same.

\section{Limitations}

Larger Sample size and more time duration is required to overcome the bias of higher bilirubin levels at start of phototherapy even after effective randomisation for better comparison of both groups.

\section{Funding: Nil \\ Conflict of interest: Nil \\ Permission from IRB: Yes}

\section{References}

1.Kliegman RM, Behrman RE, Jenson HB, Stanton BF. Nelson Textbook of Paediatrics $18^{\text {th }}$ edition. Saunders Elsevier Publications 2007;102.3: 756-772

2. Mccandles, David W. History of Jaundice Kernicterus, Contemporary Clinical Neurosciences $14^{\text {th }}$ edition. Humana press2011: 286-290.

3. Baty JM, Blackfan KD \& Diamond LK. Blood studies in infants and in children. I. Erythroblastic anemia; a clinical and pathologic study. American Journal of Diseases in Childhood 1932;43(3):667-704.

4. Hansen TW. Pioneers in the scientific study of neonatal jaundice and kernicterus. Pediatrics 2000; 106(2):E15.

5. Brown AK, Kim MH, Wu PY, Bryla DA. Efficacy of phototherapy in prevention and management of neonatal hyperbilirubinemia. Pediatrics. 1985 Feb;75(2 Pt 2):393400.

6. Tan KL, Lim GC, Boey KW. Efficacy of "highintensity" blue-light and "standard" daylight phototherapy for non-haemolytic hyperbilirubinaemia. Acta Paediatr. 1992 Nov;81(11):870-4.

7. Cremer RJ, Perryman PW, Richards DH. Influence of light on the hyperbilirubinaemia of infants Lancet. 1958 May 24;1(7030):1094-7. 
8. Ostrow JD. Mechanism of bilirubin photo degradation. Semin Hematol. 1972 Apr;9(2):113-25.

9. Lightner et al. Bilirubin photooxidation products in the urine of jaundiced neonates receiving phototherapy; Pediatric Research 1984;18(8):696-700.

10. Prates et al. Laser investigation of bilirubinphotobilirubin photoconversion. Pediatr Res. 1985 Feb;19(2):166-71.

11. Ennever JF. Blue light, green light, white light, more light: treatment of neonatal jaundice. Clin Perinatol. 1990 Jun;17(2):467-81.

12.Agarwal R, Deorari A, Paul VK. Jaundice in newborn - AIIMS Protocols in Neonatology $1^{\text {st }}$ edition CBS publishers 2015; 131-133

13. Subramanian, et al. Evaluation Of phototherapy devices. Indian Pediatr. 2011 Sep;48(9):689-96. Epub 2010 Nov 30

14. Maisels MJ, Kring EA, DeRidder J. Randomized controlled trial of light-emitting diode phototherapy.Journal of Perinatology 2007;27(9):565567.

15. Seidman DS, Moise J, Ergaz Z, Laor A, Vreman HJ, Stevenson DK, et al. A new blue light-emitting phototherapy device: A prospective randomized controlled study. Journal of Pediatrics 2000;136(6):771774.

16. Tan KL. Efficacy of bidirectional fiberoptic phototherapy for neonatal hyperbilirubinemia. Pediatrics1997;99(5):E13.

17. Seidman DS, Moise J, Ergaz Z, et al. A prospective randomized controlled study of phototherapy using blue and blue-green light-emitting devices, and conventional halogen-quartz phototherapy .J Perinatol. 2003 Mar;23(2):123-7.

18. Rosen D, Rosen A. inventors; Therapeutic Method and Internally Illuminated Garment for the Management Disorders Treatable by Phototherapy. US Patent Number 6045575. 2000. Available at: www.google.com/patents/US6045575.

19. Rosen H, Rosen A, Rosen D, Onaral B, Hiatt M. Use of a Light Emitting Diode (LED) array for bilirubin phototransformation. Conf Proc IEEE Eng Med Biol Soc. $2005 ; 7: 7266-8$.
20. Vreman HJ, Wong RJ, Stevenson DK, Route RK, Reader SD, Fejer MM, Gale R \& Seidman DS. LightEmitting Diodes: A novel light source for phototherapy. Pediatric Research1998; 44(5): 804-809.

21. Agarwal R, Kaushal M, Aggarwal R et al. Early neonatal hyperbilirubinemia using first day serum bilirubin level. Indian Pediatrics2002; 39(8):724-730.

22. Maisels MJ, Baltz RD, Bhutani V, Newman TB, Palmer H, Rosenfeld W et al. Management of hyperbilirubinemia in the newborn infant 35 or more weeks of gestation. Pediatrics2004; 114: 297-316.

23. American Academy of Pediatrics Subcommittee on Hyperbilirubinemia. Management of hyperbilirubinemia in the newborn infant 35 or more weeks of gestation. Pediatrics. 2004 Jul;114(1):297-316.

24. Bhutani V, Gourley GR, Adler S, Kreamer B, Dalman C, Johnson LH. Noninvasive measurement of total serum bilirubin in a multiracial predischarge newborn population to assess the risk of severe hyperbilirubinemia. Pediatrics 2000; 106(2):E16.

25. Kumar P, Jain N Thakre R, Murki S, Venkataseshan S. Management of hyperbilirubinemia. Evidence based clinical practice guidelines-. National Neonatal Forum of India. October 2010: 139-151.

26. Olav, Kallenburg. Foundations of Modern Probability. Spinger series in statistics $2^{\text {nd }}$ edition 2002;650 .

27. Kumar P, Murki S, Malik GK, Chawla D, Deorari AK, Karthi N, et al. Light emitting diodes versus compact fluorescent tubes for phototherapy in neonatal jaundice: a multi center randomized controlled trial. Indian Pediatrics 2010;47(2):131-137.

28. Kumar P, Chawla D, Deorari A. Light-emitting diode phototherapy for unconjugated hyperbilirubinaemia in neonates. Cochrane Database Syst Rev. 2011 Dec 7;(12):CD007969. doi: 10.1002/14651858.CD007969.pub2..

29. Martins BM, Carvalho MD, Moreira ME, Lopes JM. Efficacy of new microprocessed phototherapy system with five high intensity light emitting diodes (Super LED). Journal of Pediatrics (Rio J) 2007;83(3):253-258.

30. Karagöl BS, Erdeve O, Atasay B, Arsan S. Efficacy Of Light Emitting Diode phototherapy in comparison to conventional phototherapy in neonatal jaundice. Journal of Ankara University Faculty of Medicine 2007; 60(1):3134. 
31. Colindres V, Rountree C, Oden M et al. Prospective randomized controlled study comparing low-cost LED and conventional phototherapy for treatment of neonatal hyperbilirubinemia. Journal of Tropical Pediatrics 2011;58(03):178-183.

\section{How to cite this article?}

Reddy TR, Prasad PK, Parakh H, Nagar P. Light-emitting Diodes versus Compact Fluorescent Tubes for Phototherapy in Neonatal Jaundice: A randomised control trial. Pediatr Rev: Int J Pediatr Res 2014;1(3):72-79. doi:10.17511/ijpr.2014.i03.02 